\title{
CXCR7-mediated progression of osteosarcoma in the lungs
}

\author{
E Goguet-Surmenian ${ }^{1,2}$, P Richard-Fiardo ${ }^{1,2}$, E Guillemot $^{1,2}$, M Benchetrit $^{1,3}$, A Gomez-Brouchet ${ }^{4}$, P Buzzo $^{5}$, \\ B Karimdjee-Soilihi ${ }^{1,2,6}$, P Alemanno ${ }^{6}$, J-F Michiels ${ }^{1,3}$, A Schmid-Alliana ${ }^{1,2,7}$ and H Schmid-Antomarchi ${ }^{*}, 1,2,7$ \\ ${ }^{1}$ Université de Nice Sophia-Antipolis, UFR Sciences, Nice 06108, France; ${ }^{2}$ CNRS 3472, Nice 06202, France; ${ }^{3}$ Centre Hospitalier \\ Universitaire, Laboratoire Central d'Anatomie Pathologique, Hôpital Pasteur, Nice 06002, France; ${ }^{4}$ Service d'Anatomie et \\ Cytologie Pathologiques, CHU Rangueil, Toulouse 31400, France; ${ }^{5}$ Département de Pharmacie, Centre Antoine Lacassagne, \\ Nice 06189, France and ' Polyclinique Saint Jean, Cagnes/mer 06800, France
}

Background: Osteosarcoma (OS) is the most frequent primary malignant bone tumour in children and adolescents with a high propensity for lung metastasis. Chemokines and chemokine receptors have been described to have an important role in many malignancies including OS. The aim of this study was to investigate the expression of CXCR7 receptor in OS tissues and its role in the progression of the disease in the lungs.

Methods: Immunohistochemistry was used to study CXCR7 expression in primary tumours and metastatic tissues from patients with OS. Its contribution to tumour expansion in the lungs has been also assessed using animal models and synthetic-specific CXCR7 ligands.

Results: CXCR7 was expressed on human primary bone tumours and on lung metastases. Its expression was predominantly located on tumour-associated blood vessels. Mice challenged with OS cells and systematically treated with synthetic CXCR7 ligands presented a significant reduction of lung nodules compared with untreated mice.

Conclusion: This study shows that CXCR7 has a critical role in OS progression in the lungs, where are expressed CXCR7 ligands, especially CXCL12. Moreover, we highlight that synthetic CXCR7 ligands could represent a powerful therapeutic tool to impede lung OS progression.

Osteosarcoma (OS) is the most common primary malignant bone tumour in children and adolescents. Despite significant improvements made over the past several decades in the therapeutic approach of OS, patients with metastases still have a very poor prognosis (less than 20\% long-term survival). Osteosarcoma metastasises most commonly to the lungs, and pulmonary metastases are generally thought to be associated with a poor patient outcome (Aljubran et al, 2009).

Of the many factors involved in tumorigenesis, the chemokine/ chemokine-receptor system has a critical role in tumour initiation, promotion and progression. Many cancers have a complex chemokine network that influences the immune cells infiltration of a tumour, as well as growth, survival and migration of tumour cells, and angiogenesis (Johrer et al, 2008; O'Hayre et al, 2008).

Many studies have shown that the chemokine CXCL12 and its receptor CXCR4 are critical components in the regulation of tumour spread and metastasis in several types of cancer (O'Hayre et al, 2008). CXCR4 expression was previously shown in OS, but the correlation between CXCR4 level and OS prognosis is still debated (Oda et al, 2006; Lin et al, 2011; Baumhoer et al, 2012). Nevertheless, human and murine OS cell lines have been reported to express CXCR4 and, using animal models of OS, it was demonstrated that the inhibition of this chemokine receptor reduces the tumour progression in the lungs (Perissinotto et al, 2005; Kim et al, 2008).

\footnotetext{
*Correspondence: Dr H Schmid-Antomarchi; E-mail: antomarc@unice.fr

${ }^{7}$ These authors contributed equally to this work.
}

Revised 27 July 2013; accepted 29 July 2013; published online 3 September 2013

(C) 2013 Cancer Research UK. All rights reserved 0007-0920/13 
Besides CXCR4, CXCL12 has been shown to exhibit a high affinity to the receptor CXCR7/RDC-1 (Balabanian et al, 2005; Burns et al, 2006). The expression of CXCR7 has been reported in a variety of tumour cell lines and human tumour samples (Burns et al, 2006; Miao et al, 2007; Meijer et al, 2008; Wang et al, 2008; Calatozzolo et al, 2010; Grymula et al, 2010; Hattermann et al, 2010; Kollmar et al, 2010; Luker et al, 2010; Miekus et al, 2010; Sun et al, 2010; Zheng et al, 2010; Guillemot et al, 2012). Moreover, tumour growth and aggressiveness are often correlated with the alteration of the receptor expression (Bennani-Baiti et al, 2010; D'Alterio et al, 2010; Grymula et al, 2010). A number of these studies have reported the critical role of CXCR7 in tumour vascular formation, angiogenesis and growth promotion of various cancers in vivo (Burns et al, 2006; Miao et al, 2007; Meijer et al, 2008; Wang et al, 2008; Kollmar et al, 2010; Guillemot et al, 2012). However, the role of CXCR7 in OS has not yet been clearly evaluated. The present study was carried out to assess the contribution of CXCR7 receptor in the pulmonary expansion of OS. First, we investigated whether CXCR7 was expressed in OS cells and tissues of human and murine origins. Then, we explored whether the interactions between CXCR7 and its ligands are critical components for OS progression in the lungs. To test this hypothesis, experimental lung tumours of OS as well as specific synthetic CXCR7 ligands were used.

Our results indicate that CXCR7 mainly expressed on tumourassociated vessels can regulate OS progression in the lungs, where are expressed CXCR7 ligands, and thus could have a critical role in the metastatic process of OS.

\section{MATERIALS AND METHODS}

Human tissues. Tumour tissues from surgical resection specimens were obtained from the Department of Anatomopathology of Rangueil Hospital (Toulouse, France). All patients gave written informed consent and the study was approved by the hospital's ethics committee. Ten OSs derived from primary skeletal lesions and 8 cases from lung metastatic lesions (corresponding to lung recurrences in 8 out of 10 patients). Standart histological diagnosis was performed on $5-\mu \mathrm{m}$ sections of formalin-fixed and paraffinembedded tissues. The histological diagnosis was reviewed by A.G-B (MD, PhD).

Tumour cell lines. The K7M2 cell line (mouse OS) was obtained from American Type Culture Collection (LGC Promochem, Molsheim, France). The SaOS-LM7 cell line (human OS) was kindly provided by E Kleinerman from Anderson Cancer Center (Houston, TX, USA). Cell lines were maintained in DMEM (K7M2) and in MEM (SaOS-LM7) as previously described (Pradelli et al, 2009).

Histology/immunohistochemistry. Formalin-fixed, paraffinembedded sections of primary tumour and/or metastatic tissues from patients with OS and from mouse cancer models were stained with haematoxylin and eosin for morphological evaluation. For CXCR7 immunostaining, the tissue sections were subjected for $20 \mathrm{~min}$ to heat-mediated antigen retrieval in citrate buffer $(\mathrm{pH} 6)$ before blocking in sequential peroxydase and protein block for $20 \mathrm{~min}$. Samples were incubated with anti-CXCR7 antibody clone 11G8 (R\&D Systems, Lille, France) for $45 \mathrm{~min}$ at $10 \mu \mathrm{g} \mathrm{ml}{ }^{-1}$ and $20^{\circ} \mathrm{C}$ and then, with a secondary HRP-conjugated goat anti-mouse antibody.

TaqMan real-time PCR experiments. Total RNA was extracted from mouse healthy lungs using RNeasy kit (Qiagen, Courtaboeuf, France). One microgram of total RNA was reverse-transcribed into cDNA using the Superscript III enzyme (Invitrogen, Cergy Pontoise, France), according to the manufacturer's instructions.
Real-Time PCR was performed in an ABI PRISM 7900 using TaqMan gene expression assays (Applied Biosystems, Courtaboeuf, France) with a total of $12.5 \mathrm{ng} \mathrm{cDNA}$ as a template for amplification. Cycle parameters were $50{ }^{\circ} \mathrm{C}$ for $2 \mathrm{~min}, 95^{\circ} \mathrm{C}$ for $10 \mathrm{~min}$ followed by 40 cycles of $95^{\circ} \mathrm{C}$ for $15 \mathrm{~s}$ and $60^{\circ} \mathrm{C}$ for $1 \mathrm{~min}$. Relative mRNA expression levels are presented as $\Delta \mathrm{C}_{\mathrm{T}}$, which show an inverse correlation with absolute mRNA levels. $\Delta \mathrm{C}_{\mathrm{T}}$ values were obtained by subtracting $\mathrm{C}_{\mathrm{T}}$ control (mouse $18 \mathrm{~S}, \mathrm{Mm}$ 03928990-g1) from $\mathrm{C}_{\mathrm{T}}$ target gene (mouse CXCL11 and CXCL12, $\mathrm{Mm} 00444662 \mathrm{ml}$ and $\mathrm{Mm} 00445552 \mathrm{ml}$, respectively) measured in the same RNA preparation.

Flow cytometry. K7M2 cells were preincubated with a purified rat anti-mouse CD16/CD32 monoclonal antibody (mouse BD Fc Block; BD Biosciences, Le Pont de Claix, France) and SAOS-LM7 cells, with a purified human IgG (R\&D Systems) in order to block non-specific antibody binding. Cells were then stained with a PhycoErythrin-conjugated mouse monoclonal anti-human CXCR7 antibody or with an isotype-matched control antibody (clone 11G8 or IgG1 control, R\&D Systems, $0,1 \mu \mathrm{g}$ of IgG1 per $10^{6}$ cells) for $30 \mathrm{~min}$ at $4{ }^{\circ} \mathrm{C}$. Cells were analysed using a BD FACScanto II flow cytometer.

Animal studies. All of the procedures involving animals and their care were conducted in accordance with institutional guidelines (Permit number A06-088-14) and after approval by the local ethics committee (Permit number NCA 2008-02).

Experimental lung tumours of OS, referring to the late steps of the metastatic process (i.e., extravasation from the blood stream and tumour growth in the lungs) were induced by intravenous injection of K7M2 and SaOS-LM7 cells into 6- to 8-week-old BALB/c and Nude mice (Harlan, Gannat, France), respectively, as previously described (Pradelli et al, 2009). The treatments with synthetic-specific CXCR7 ligands were delivered to mice by intraperitoneal injections of $100 \mathrm{mg} \mathrm{kg}^{-1}$ of the CCX771 compound or its early prototype, the CCX754 compound (Burns et al, 2006; Zabel et al, 2009), according to preventive or curative treatments as described below.

The preventive treatment was performed by treating mice one day before injection of K7M2 cells and for 3 consecutive days (from days -1 to day +3 ). The curative treatment was achieved by treating animals daily with synthetic CXCR7 ligands from days +5 to day +15 after the injection of K7M2 cells and from days +5 to +15 and again, days +20 to +30 following SaOS-LM7 injection. Fifteen days after the injection of the K7M2 cells or 10 weeks after the injection of the SaOS-LM7 cells, the mice were killed and the lungs were insufflated with $10 \%$ neutral-buffered formalin or with India ink dye (Williams and Lisanti, 2004) that reveals white tumour nodules against a black lung background. The extent of tumour development was assessed by recording the number of visible tumour nodules on the pleural surface and by recording the volume of all tumour nodules (cumulative volume).

Statistical analysis. Statistical comparisons were performed using the non-parametric Man-Whitney $U$-test and statistical significance was set at $P<0.05$.

\section{RESULTS}

CXCR7 expression in human tissues. CXCR7 expression was first analysed in human OS tissues derived from primary skeletal lesions $(n=10)$ and from lung metastatic lesions $(n=8)$ (Figure 1A and B, respectively) by using the CXCR7-specific monoclonal antibody 11G8 (Berahovich et al, 2010b). CXCR7 immunoreactivity was detected in at least $30 \%$ of the samples ( 3 out of 10 primary lesions, 3 out of 8 lung metastases; primary lesion and lung metastases were found together CXCR7-positive 
A
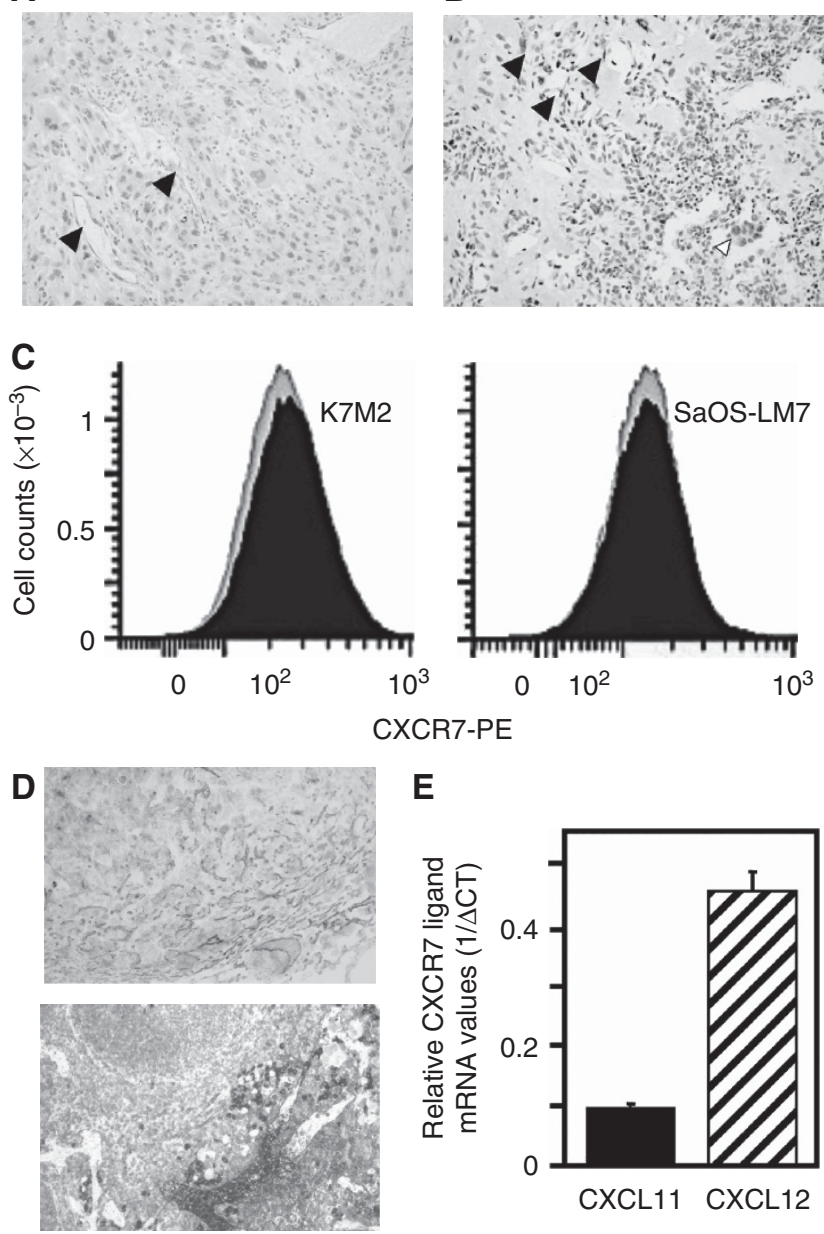

E

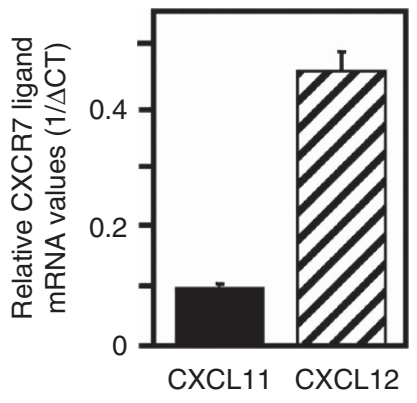

Figure 1. Expression of CXCR7 and its ligands in murine and human tissues. (A, B) Immunohistochemical analysis of CXCR7 expression on human biopsies of primary skeletal $O S(\mathbf{A})$ and lung metastatic lesions (B). The filled arrows show CXCR7-stained tumour-associated vessels, whereas the open arrow signals CXCR7-stained OS cells. Magnifications $\times 400$. (C) Flow cytometry investigation of surface CXCR7 expression on K7M2 and SaOS-LM7 cells. Grey histograms represent cells stained with the isotype-matched control antibody. Black histograms show cells stained with an anti-CXCR7 antibody. Panels are representative of two independent experiments. (D) CXCR7 immunostaining of lung sections from SaOS-LM7-bearing mice (upper panel). Spleen sections from nude mouse are used as CXCR7-positive tissue control (lower panel). Positive staining is depicted as brown. Magnification $\times 200$. (E) Quantitative real-time PCR for the analysis of CXCR7 ligands expression in mouse healthy lungs. The relative expression levels of genes were calculated using $18 \mathrm{~S}$ as a normalising gene and expressed as $1 / \Delta C_{T}$. The mean \pm s.e.m. of duplicate per condition is shown. Representative of three independent experiments.

for one patient). In both types of lesions, CXCR7-specific reactivity was mostly located on tumour-associated vessels. The number of immunoreactive tumoral vessels within a lesion varied among the sample and ranged from 30 to 50\%. Occasionally, CXCR7-specific reactivity was also apparent on tumour cells. In contrast, tumour osteoid, healthy tissues and normal vasculature were not stained by CXCR7 antibodies.

It is important to underline that we tested several other CXCR7 antibodies, one rabbit polyclonal (Abcam, PLC, Paris, France) and one mouse monoclonal (R\&D) and found discordant stainings (data not shown). Interestingly, Berahovich et al (2010a) highlighted that most CXCR7 antibodies commercially available were not specific, except for CXCR7 11G8 clone, thereby giving concrete explanation to discordant stainings that we observed with the other antibodies.

CXCR7 expression in mouse tumour cells and tissues. The CXCR7 expression was then investigated in lung tumours obtained in mice challenged with K7M2 and SaOS-LM7 OS cells. First, the cell surface CXCR7 expression was examined in vitro on both cell lines by flow cytometry, using the specific 11G8 anti-CXCR7 antibody. The expression of this receptor was undetectable in mouse K7M2 as well as in human SaOS-LM7 (Figure 1C) cells. The in vivo CXCR7 expression was then assessed in the tumour-bearing lungs from SaOS-LM7- and K7M2-inoculated mice. CXCR7 immunoreactivity was detected in all tumoural lung samples. As observed for human OS tissue samples, in SaOS-LM7 mouse lung sections (Figure 1D), CXCR7 immunostaining was mainly located on tumour-associated vessels and in a few cases, on some scarce tumour cells (not shown). In contrast, CXCR7 antibodies did not stain healthy tissues or normal vasculature. The same staining pattern was observed in the K7M2 model (data not shown).

Together, these data underline the relevance of our mouse models for human pathology study.

CXCR7 ligands expression in mouse lungs. Chemokines have a paramount role in the tumour progression through autocrine or paracrine mechanisms. We were thus interested in evaluating the lungs ability of healthy mice to produce the CXCR7 ligands. Quantitative real-time PCR analysis of CXCL11 and CXCL12 gene expression indicated that mouse lungs expressed both chemokines (Figure 1E).

CXCR7-mediated inhibition of lung nodules. We were first interested in evaluating the effects of systemic treatment with synthetic CXCR7 ligands, such as CCX754 and CCX771 compounds (Burns et al, 2006; Zabel et al, 2009), during the early stages of lung tumour formation. To this end, the effects of preventive-called treatment with CCX754, which started before OS cell inoculation and was continued two additional days, was evaluated in the model using K7M2 cells (Figure 2A). As depicted in Figure 2B, mice from both CCX754- and vehicle-treated groups developed numerous macroscopic pulmonary tumour foci. The extent of lung tumour development was significantly reduced by CCX754 treatment. CCX754-treated mice exhibited a $79 \%$ reduction in the number of lung nodules compared with vehicletreated mice (13.3 nodules versus 63.2 nodules, respectively) (Figure 2C, left panel). The inhibitory effect of this treatment was also highlighted by the cumulative tumour volume that presented a $86 \%$ reduction in CCX754-treated mice compared with vehicletreated mice $\left(8.54 \mathrm{~mm}^{3}\right.$ versus $59.2 \mathrm{~mm}^{3}$ respectively) (Figure $2 \mathrm{C}$, right panel). Similar effects were obtained with the CCX771 compound (data not shown) that was used in the following experiments.

The effects of systemic CCX771 treatment were then evaluated on pre-established OS lung tumours. With this aim, K7M2inocculated mice were subjected to curative CCX771 treatment or vehicle control (Figure 3A) and examined for tumour development (Figure 3B-D). As shown in Figure 3B, all mice from both groups developed macroscopic pulmonary tumour foci. However, there was a significant metastatic burden reduction in the lungs of CCX771-treated mice compared with the control group, as reflected in the number of foci (54.4 nodules versus 103 nodules, respectively) and in the cumulative tumour volume $\left(36.5 \mathrm{~mm}^{3}\right.$ versus $82.2 \mathrm{~mm}^{3}$, respectively) (Figure $3 \mathrm{C}$ ). Those data were confirmed by the histological analysis of lungs showing fewer and smaller tumour foci in CCX771-treated mice compared with vehicle-treated mice (Figure 3D). 
A

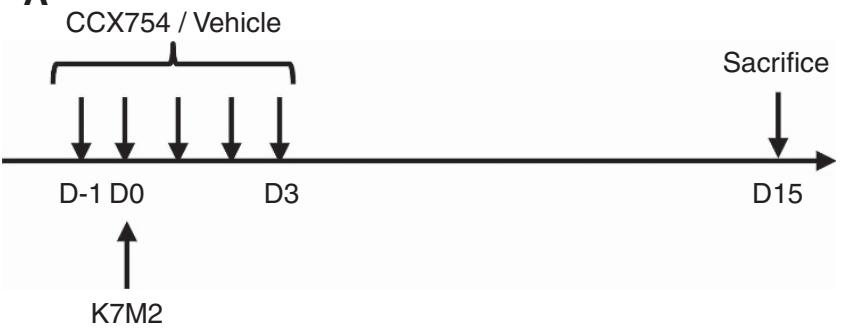

B

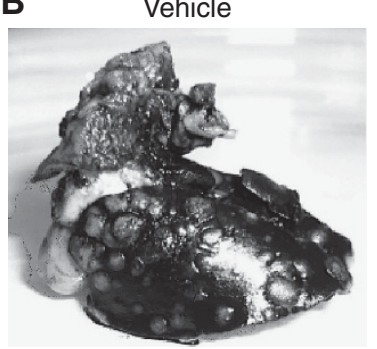

Tumour

incidence : 10/10

C
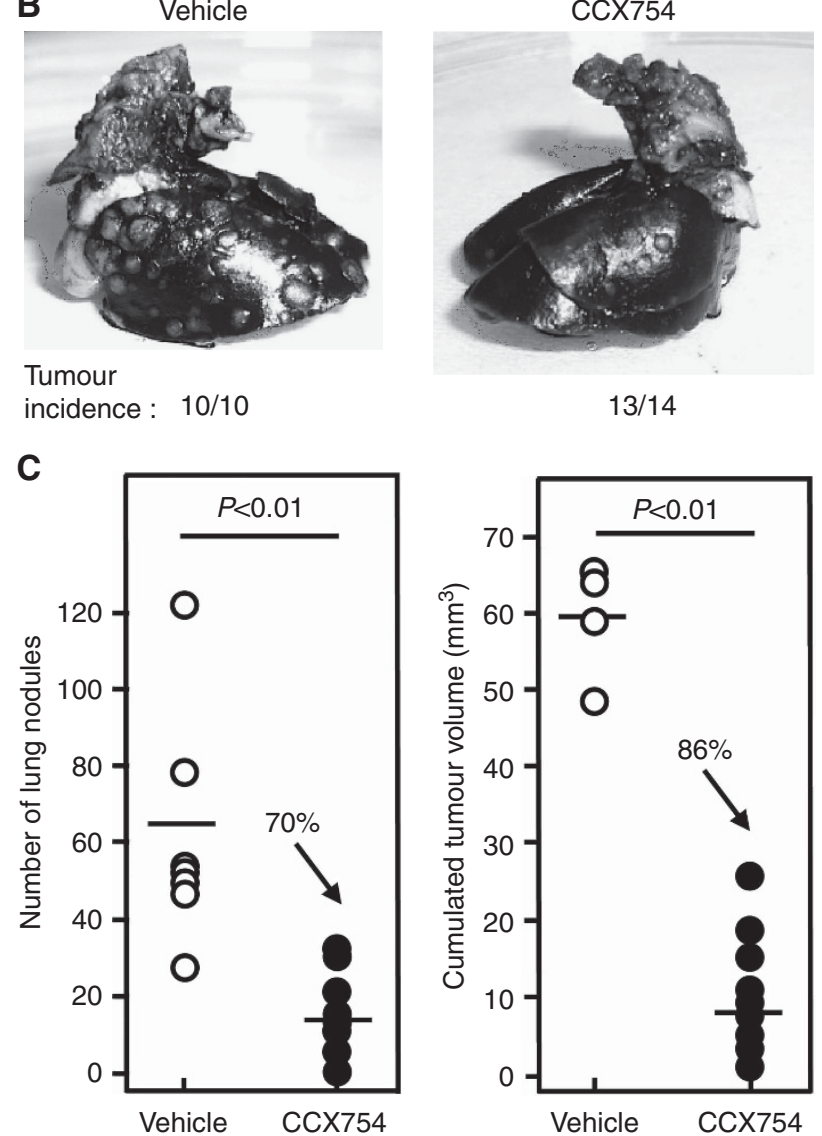

$13 / 14$

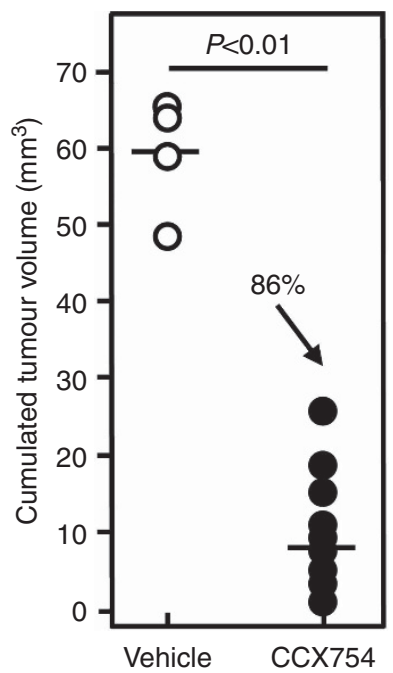

A

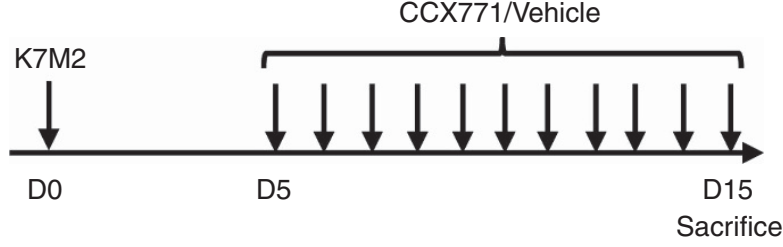

B

Figure 2. Effects of CXCR7-targeted treatment in the prevention of OS lung development. (A) Schematic representation of the preventive CXCR7-targeted treatment. K7M2 cells were injected into the tail vein of mice pretreated with vehicle or CCX754 compound, as described in the Materials and Methods section. Fifteen days later, mice were killed for lung examination ( $n=10-14$ mice per group). (B) Representative crude photographs of India ink-stained lungs harvested from vehicleand CCX754-treated mice. (C) Extent of tumour development by recording the number of pulmonary nodules (left panel) and by measuring the cumulative tumour volume (right panel) in the lungs. Each dot represents the number or the cumulative volume of nodules for one mouse and the middle line represents the median values of each group of mice.

The effects of systemic treatment with synthetic CXCR7 ligands were next evaluated in human cells using the SaOS-LM7 model. SaOS-LM7-inoculated mice were subjected to curative CCX771 treatment or vehicle (Figure 4A) and the extent of tumour development was assessed as described above. As shown in Figure 4B, all vehicle-treated mice developed lung tumours, whereas only $50 \%$ of CCX771-treated mice displayed lung macroscopic nodules. Moreover, CCX771-treated mice exhibited fewer lung nodules than the control group (8.7 nodules versus 21,6
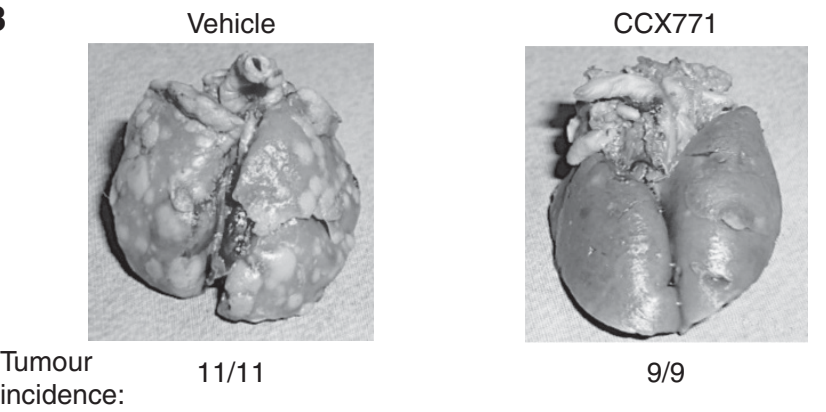

C
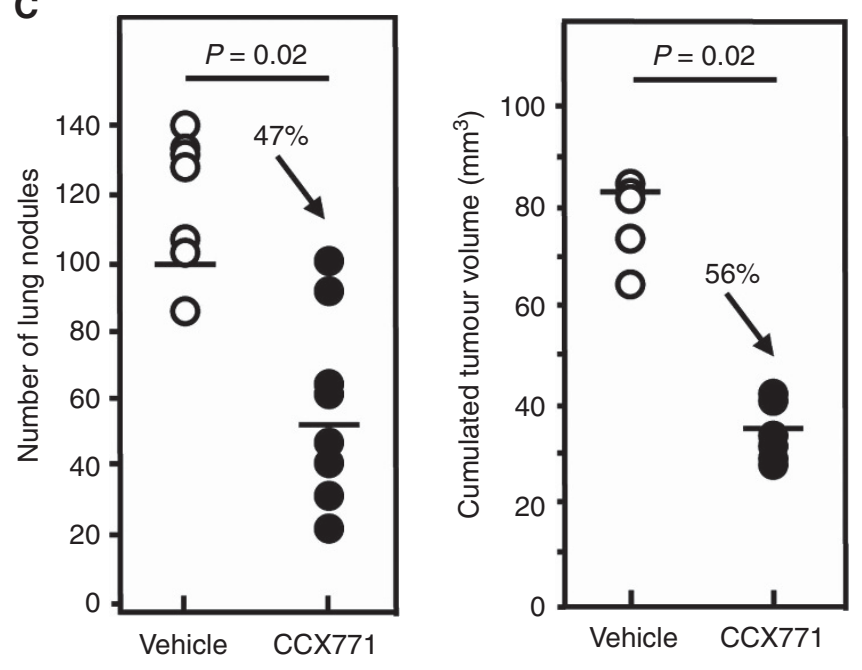

D
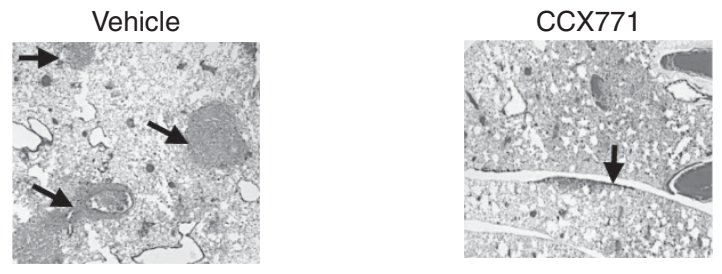

Figure 3. Effects of CXCR7-targeted treatment on pre-established K7M2 lung tumours. (A) Schematic representation of the curative CXCR7-targeted treatment. Mice were injected with K7M2 cells into the tail vein before receiving intraperitoneal injections of CCX771 or vehicle, as described in the Materials and Methods section. Fifteen days after injection of the K7M2 cells, mice were killed for lung examination ( $n=9-11$ mice per group). (B) Representative crude photographs of the lungs of vehicle-treated and CCX771-treated tumour-bearing mice. (C) Extent of tumour development by recording the number of pulmonary nodules (left panel) and by measuring the cumulative tumour volume (right panel) in the lungs. Each dot represents the number or the cumulative volume of nodules for one mouse and the middle line represents the median values of each group of mice. (D) Representative haematoxylin/eosin staining of lungs from vehicletreated and CCX771-treated tumour-bearing mice. Arrows show metastases. Magnifications $\times 40$.

nodules, respectively) (Figure 4C, left panel). This inhibitory effect of CCX771 compound was also reflected in the cumulative tumour volume with a $65 \%$ reduction compared with the vehicle-treated 
A

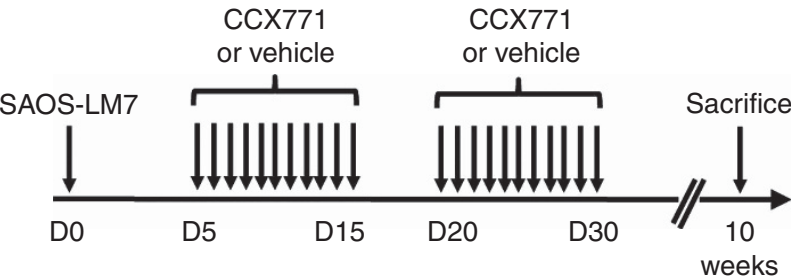

B

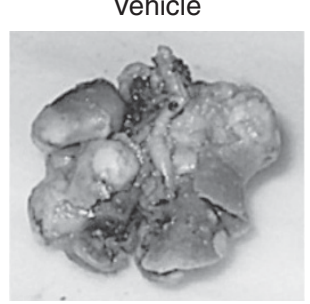

Tumour incidence: 14/14

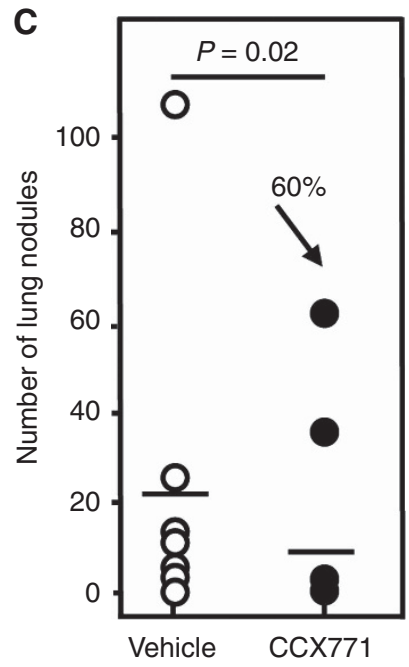

D

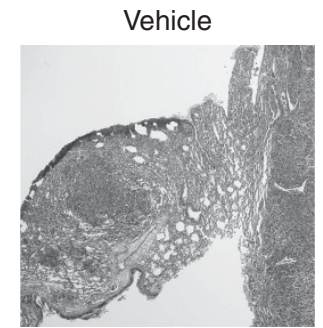

CCX771

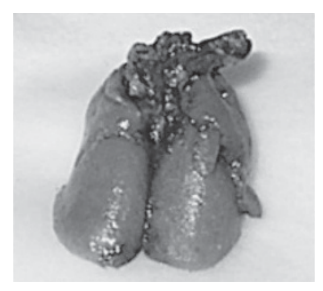

$7 / 14$
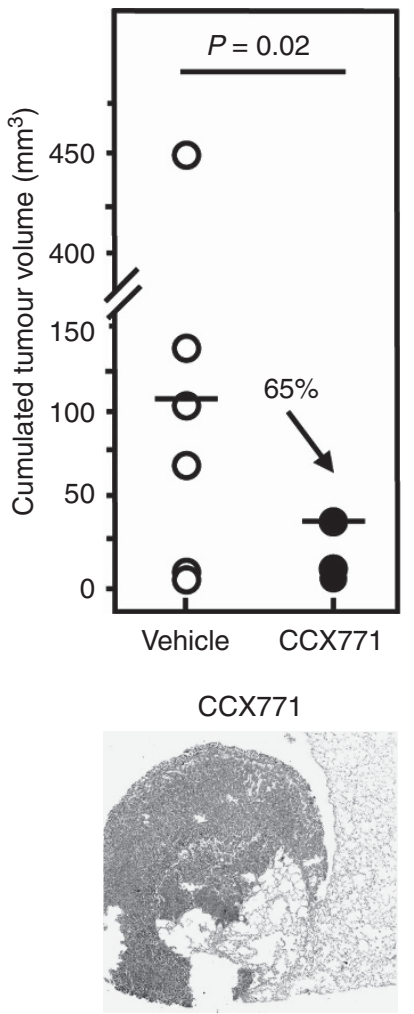

Figure 4. Effects of CXCR7-targeted treatment on pre-established SaOS-LM7 lung tumours. (A) Schematic representation of the curative CXCR7-targeted treatment. Mice were injected with SaOS-LM7 cells into the tail vein before receiving intraperitoneal injections of CCX771 or vehicle, as described in the Materials and Methods section. Ten weeks after injection of the SaOS-LM7 cells, mice were killed for lung examination ( $n=14$ mice per group). (B) Representative crude photographs of the lungs of vehicle-treated and CCX771-treated tumour-bearing mice. (C) Extent of tumour development by recording the number of pulmonary nodules (left panel) and by measuring the cumulative tumour volume (right panel) in the lungs. Each dot represents the number or the cumulative volume of nodules for one mouse and the middle line represents the median values of each group of mice. (D) Representative haematoxylin/eosin staining of lungs from vehicletreated and CCX771-treated tumour-bearing mice. Deep purple areas show metastases. Magnifications $\times 40$.

group ( $39.1 \mathrm{~mm}^{3}$ versus $110 \mathrm{~mm}^{3}$, respectively) (Figure 4C, right panel). These data were confirmed by the histological analysis of lungs, showing an almost complete invasion of pulmonary tissues

by tumour cells in control group, whereas the tumour burden was limited to some lung tissue areas in the group of CCX771-treated mice (Figure 4D).

\section{DISCUSSION}

This study tested the hypothesis that CXCR7 is critical for the progression of OS in the lungs. Here we show that CXCR7 is expressed in human OS tissues, more specifically in primary bone tumours as well as in lung metastases. We found that this receptor was expressed mainly on tumour-associated blood vessels and rarely on tumour cells and not at all on healthy bone, lungs or vasculature. These results were consistent with studies on other human cancers that had also described CXCR7 expression on the neovasculature associated with tumour and not on most nontransformed cells or on non-tumour vasculature (Miao et al, 2007; Guillemot et al, 2012; Monnier et al, 2012). These data suggested that CXCR7 may have an important role during the development of OS lung metastasis and have thus prompted us to assess their in vivo relevance in OS.

To investigate whether CXCR7 affects OS expansion in the lungs, we tested whether a systemic treatment with specific synthetic CXCR7 ligands could affect local growth of preestablished lung tumours in mice. Indeed, this treatment has been proven to strongly reduce the tumour expansion within the lungs of both SaOS-LM7- and K7M2-inoculated mice. De facto, CXCR7 may be viewed as a key factor in the progression of OS in the lungs. In addition, preventive CXCR7-targeted treatment administrated to mice before the OS cell inoculation significantly reduced tumour formation, also pointing to a role of CXCR7 during the early stages of lung development of OS.

Collectively, these results highlight an essential role of CXCR7 in both the early and the late expansion stages of OS in the lungs and provide the first evidence of the potential of CXCR7-targeted strategies to cure or prevent OS lung expansion.

Despite numerous studies investigating the role of CXCR7 in tumorigenesis of a variety of tumours, the mechanism of action for this receptor remains unclear. Although our study did not allow us to elucidate the molecular mechanisms by which CXCR7 controls OS progression, our data nevertheless suggested possible mechanisms of action.

CXCR7 is a second receptor for CXCL12 that binds this chemokine with greater affinity than CXCR4. Several studies in zebrafish development and in mammalian systems suggest that CXCR7 primarily functions to sequester CXCL12 (Boldajipour et al, 2008; Luker et al, 2010; Naumann et al, 2010). Thus, reducing CXCL12 from its surrounding environment, CXCR7 shapes the extracellular CXCL12 gradient that directs the migration of CXCR4-expressing cells. Computational modelling revealed that CXCL12-producing cells and CXCR7-expressing cells functioned in a source-sink model of gradient formation for CXCR4dependent chemotaxis (Torisawa et al, 2010). In addition to generating chemotactic gradients, CXCR7 may also maintain CXCL12/CXCR4 signalling by limiting desensitisation of CXCR4 during chronic exposure to CXCL12. As evidenced by our PCR experiments and reported by others (Muller et al, 2001), natural CXCR7 ligands, especially CXCL12, are expressed in healthy lungs. CXCR4 expression has been described on vascular endothelial cells and on their circulating progenitors (Miao et al, 2007; Dai et al, 2011; Monnier et al, 2012; Yan et al, 2012) and several reports have highlighted OS cells as CXCR4-expressing cells (Perissinotto et al, 2005; Kim et al, 2008). As CXCR7 serves as scavenger for CXCL12, it can be suggested that in vivo blockade of CXCR7 might result in enhanced levels of CXCL12. Indeed, it has been reported (Wang et al, 2012) that in vivo CCX754 treatment increase the levels of 
CXCL12 in peripheral blood. Thus, it can be assumed that increasing amounts of chemokine released in the peripheral blood impedes CXCL12 gradient formation and promotes the desensitisation of CXCR4. Consequently, the migration and/or proliferation of $\mathrm{CXCR}^{+}{ }^{+}$cells, especially OS cells, endothelial and endothelial-progenitor cells, would be altered and tumour expansion slowed or prevented. Thus, we could explain, as previously shown by Baumhoer et al (2012), that strong expression of CXCL12 is associated with a favourable outcome in OS.

CXCR7 is phylogenetically closely related to chemokine receptors but fails to couple to $G$ proteins and to induce typical chemokine receptor-mediated cellular responses (Fredriksson et al, 2003; Burns et al, 2006; Thelen and Thelen, 2008). Unlike classical chemokine receptors, CXCR7 signals through $\beta$-arrestins in response to ligand binding without detectable activation of $\mathrm{G}$ proteins. $\beta$-Arrestins were initially discovered as negative regulators of $\mathrm{G}$ protein-mediated signalling by seven-transmembrane receptors (Lohse et al, 1990), but it was subsequently discovered that they were themselves capable of positively regulating cell signalling. Chemical compounds such as CCX771 and their precursors, originally developped by ChemoCentryx as « CXCR7 inhibitors ", have shown agonistic activity in terms of CXCR7-dependent $\beta$-arrestin recruitment (Zabel et al, 2009). Consequently, we cannot exclude that the synthetic ligands of CXCR7 impede the OS lung expansion through mechanisms other than the chemokine scavenging one.

In summary, this study shows that CXCR7 has a critical role in OS progression in the lungs, where are expressed CXCR7 ligands, especially CXCL12. Moreover, we highlight that synthetic CXCR7 ligands can represent a powerful therapeutic tool to suppress or prevent lung OS progression.

\section{ACKNOWLEDGEMENTS}

We thank Eugenie Kleinerman from MD Anderson Cancer Center of the University of Texas for providing SaOS-LM7 cell line and to Dr Mark ET Penfold (ChemoCentryx Inc.) for providing the synthetic CXCR7 ligands CCX771 and CCX754. We also thank Pr Mery Tulic (University of Western Australia) for her help with English language and all the technicians of the Animal Facility of INSERM Unit 1065 (Nice, France) for the excellent technical assistance. This research was supported by the French National Institute of Health and Medical Research (INSERM), the French National Center for Scientific Research (CNRS), by the French Cancer Research Association (ARC, Grant 4034) and by the Cancéropôle PACA (ACI 42259). P Richard-Fiardo is a recipient of an ARC postdoctoral fellowship.

\section{CONFLICT OF INTEREST}

The authors declare no conflict of interest.

\section{REFERENCES}

Aljubran AH, Griffin A, Pintilie M, Blackstein M (2009) Osteosarcoma in adolescents and adults: survival analysis with and without lung metastases. Ann Oncol 20(6): 1136-1141.

Balabanian K, Lagane B, Infantino S, Chow KY, Harriague J, Moepps B, Arenzana-Seisdedos F, Thelen M, Bachelerie F (2005) The chemokine SDF-1/CXCL12 binds to and signals through the orphan receptor RDC1 in T lymphocytes. J Biol Chem 280(42): 35760-35766.

Baumhoer D, Smida J, Zillmer S, Rosemann M, Atkinson MJ, Nelson PJ, Jundt G, von Luettichau I, Nathrath M (2012) Strong expression of
CXCL12 is associated with a favorable outcome in osteosarcoma. Mod Pathol 25(4): 522-528.

Bennani-Baiti IM, Cooper A, Lawlor ER, Kauer M, Ban J, Aryee DN, Kovar H (2010) Intercohort gene expression co-analysis reveals chemokine receptors as prognostic indicators in Ewing's sarcoma. Clin Cancer Res 16(14): 3769-3778.

Berahovich RD, Penfold ME, Schall TJ (2010a) Nonspecific CXCR7 antibodies. Immunol Lett 133(2): 112-114.

Berahovich RD, Zabel BA, Penfold ME, Lewen S, Wang Y, Miao Z, Gan L, Pereda J, Dias J, Slukvin, II, McGrath KE, Jaen JC, Schall TJ (2010b) CXCR7 protein is not expressed on human or mouse leukocytes. J Immunol 185(9): 5130-5139.

Boldajipour B, Mahabaleshwar H, Kardash E, Reichman-Fried M, Blaser H, Minina S, Wilson D, Xu Q, Raz E (2008) Control of chemokine-guided cell migration by ligand sequestration. Cell 132(3): 463-473.

Burns JM, Summers BC, Wang Y, Melikian A, Berahovich R, Miao Z, Penfold ME, Sunshine MJ, Littman DR, Kuo CJ, Wei K, McMaster BE, Wright K, Howard MC, Schall TJ (2006) A novel chemokine receptor for SDF-1 and I-TAC involved in cell survival, cell adhesion, and tumour development. J Exp Med 203(9): 2201-2213.

Calatozzolo C, Canazza A, Pollo B, Pierro ED, Ciusani E, Maderna E, Salce E, Sponza V, Frigerio S, Meco FD, Schinelli S, Salmaggi A (2010) Expression of the new CXCL12 receptor, CXCR7, in gliomas. Cancer Biol Ther 11(2): 242-253.

D’Alterio C, Consales C, Polimeno M, Franco R, Cindolo L, Portella L, Cioffi M, Calemma R, Marra L, Claudio L, Perdona S, Pignata S, Facchini G, Carteni G, Longo N, Pucci L, Ottaiano A, Costantini S, Castello G, Scala S (2010) Concomitant CXCR4 and CXCR7 expression predicts poor prognosis in renal cancer. Curr Cancer Drug Targets 10(7): $772-781$.

Dai X, Tan Y, Cai S, Xiong X, Wang L, Ye Q, Yan X, Ma K, Cai L (2011) The role of CXCR7 on the adhesion, proliferation and angiogenesis of endothelial progenitor cells. J Cell Mol Med 15(6): 1299-1309.

Fredriksson R, Lagerstrom MC, Lundin LG, Schioth HB (2003) The $\mathrm{G}$-protein-coupled receptors in the human genome form five main families. Phylogenetic analysis, paralogon groups, and fingerprints. Mol Pharmacol 63(6): 1256-1272.

Grymula K, Tarnowski M, Wysoczynski M, Drukala J, Barr FG, Ratajczak J, Kucia M, Ratajczak MZ (2010) Overlapping and distinct role of CXCR7-SDF-1/ITAC and CXCR4-SDF-1 axes in regulating metastatic behavior of human rhabdomyosarcomas. Int J Cancer 127(11): 2554-2568.

Guillemot E, Karimdjee-Soilihi B, Pradelli E, Benchetrit M, GoguetSurmenian E, Millet MA, Larbret F, Michiels JF, Birnbaum D, Alemanno P, Schmid-Antomarchi H, Schmid-Alliana A (2012) CXCR7 receptors facilitate the progression of colon carcinoma within lung not within liver. Br J Cancer 107(12): 1944-1949.

Hattermann K, Held-Feindt J, Lucius R, Muerkoster SS, Penfold ME, Schall TJ, Mentlein R (2010) The chemokine receptor CXCR7 is highly expressed in human glioma cells and mediates antiapoptotic effects. Cancer Res 70(8): 3299-3308.

Johrer K, Pleyer L, Olivier A, Maizner E, Zelle-Rieser C, Greil R (2008) Tumour-immune cell interactions modulated by chemokines. Expert Opin Biol Ther 8(3): 269-290.

Kim SY, Lee CH, Midura BV, Yeung C, Mendoza A, Hong SH, Ren L, Wong D, Korz W, Merzouk A, Salari H, Zhang H, Hwang ST, Khanna C, Helman LJ (2008) Inhibition of the CXCR4/CXCL12 chemokine pathway reduces the development of murine pulmonary metastases. Clin Exp Metastasis 25(3): 201-211.

Kollmar O, Rupertus K, Scheuer C, Nickels RM, Haberl GC, Tilton B, Menger MD, Schilling MK (2010) CXCR4 and CXCR7 regulate angiogenesis and CT26.WT tumor growth independent from SDF-1. Int J Cancer 126(6): 1302-1315.

Lin F, Zheng SE, Shen Z, Tang LN, Chen P, Sun YJ, Zhao H, Yao Y (2011) Relationships between levels of CXCR4 and VEGF and blood-borne metastasis and survival in patients with osteosarcoma. Med Oncol 28(2): 649-653.

Lohse MJ, Benovic JL, Codina J, Caron MG, Lefkowitz RJ (1990) Beta-Arrestin: a protein that regulates beta-adrenergic receptor function. Science 248(4962): 1547-1550.

Luker KE, Steele JM, Mihalko LA, Ray P, Luker GD (2010) Constitutive and chemokine-dependent internalization and recycling of CXCR7 in breast cancer cells to degrade chemokine ligands. Oncogene 29(32): 4599-4610. 
Meijer J, Ogink J, Roos E (2008) Effect of the chemokine receptor CXCR7 on proliferation of carcinoma cells in vitro and in vivo. Br J Cancer 99(9): 1493-1501.

Miao Z, Luker KE, Summers BC, Berahovich R, Bhojani MS, Rehemtulla A, Kleer CG, Essner JJ, Nasevicius A, Luker GD, Howard MC, Schall TJ (2007) CXCR7 (RDC1) promotes breast and lung tumour growth in vivo and is expressed on tumor-associated vasculature. Proc Natl Acad Sci USA 104(40): 15735-15740.

Miekus K, Jarocha D, Trzyna E, Majka M (2010) Role of I-TAC-binding receptors CXCR3 and CXCR7 in proliferation, activation of intracellular signaling pathways and migration of various tumour cell lines. Folia Histochem Cytobiol 48(1): 104-111.

Monnier J, Boissan M, L'Helgoualc'h A, Lacombe ML, Turlin B, Zucman-Rossi J, Theret N, Piquet-Pellorce C, Samson M (2012) CXCR7 is up-regulated in human and murine hepatocellular carcinoma and is specifically expressed by endothelial cells. Eur J Cancer 48(1): 138-148.

Muller A, Homey B, Soto H, Ge N, Catron D, Buchanan ME, McClanahan T, Murphy E, Yuan W, Wagner SN, Barrera JL, Mohar A, Verastegui E, Zlotnik A (2001) Involvement of chemokine receptors in breast cancer metastasis. Nature 410(6824): 50-56.

Naumann U, Cameroni E, Pruenster M, Mahabaleshwar H, Raz E, Zerwes HG, Rot A, Thelen M (2010) CXCR7 functions as a scavenger for CXCL12 and CXCL11. PLoS One 5(2): e9175.

O'Hayre M, Salanga CL, Handel TM, Allen SJ (2008) Chemokines and cancer: migration, intracellular signalling and intercellular communication in the microenvironment. Biochem J 409(3): 635-649.

Oda Y, Yamamoto H, Tamiya S, Matsuda S, Tanaka K, Yokoyama R, Iwamoto Y, Tsuneyoshi M (2006) CXCR4 and VEGF expression in the primary site and the metastatic site of human osteosarcoma: analysis within a group of patients, all of whom developed lung metastasis. Mod Pathol 19(5): 738-745.

Perissinotto E, Cavalloni G, Leone F, Fonsato V, Mitola S, Grignani G, Surrenti N, Sangiolo D, Bussolino F, Piacibello W, Aglietta M (2005) Involvement of chemokine receptor 4/stromal cell-derived factor 1 system during osteosarcoma tumor progression. Clin Cancer Res 11(2 Pt 1): 490-497.

Pradelli E, Karimdjee-Soilihi B, Michiels JF, Ricci JE, Millet MA, Vandenbos F, Sullivan TJ, Collins TL, Johnson MG, Medina JC, Kleinerman ES, SchmidAlliana A, Schmid-Antomarchi H (2009) Antagonism of chemokine receptor CXCR3 inhibits osteosarcoma metastasis to lungs. Int $J$ Cancer 125(11): 2586-2594.

Sun X, Cheng G, Hao M, Zheng J, Zhou X, Zhang J, Taichman RS, Pienta KJ, Wang J (2010) CXCL12/CXCR4/CXCR7 chemokine axis and cancer progression. Cancer Metastasis Rev 29(4): 709-722.

Thelen M, Thelen S (2008) CXCR7, CXCR4 and CXCL12: an eccentric trio? J Neuroimmunol 198(1-2): 9-13.

Torisawa YS, Mosadegh B, Bersano-Begey T, Steele JM, Luker KE, Luker GD, Takayama S (2010) Microfluidic platform for chemotaxis in gradients formed by CXCL12 source-sink cells. Integr Biol (Camb) 2(11-12): 680-686.

Wang H, Beaty N, Chen S, Qi CF, Masiuk M, Shin DM, Morse 3rd HC (2012) The CXCR7 chemokine receptor promotes B-cell retention in the splenic marginal zone and serves as a sink for CXCL12. Blood 119(2): $465-468$.

Wang J, Shiozawa Y, Wang J, Wang Y, Jung Y, Pienta KJ, Mehra R, Loberg R, Taichman RS (2008) The role of CXCR7/RDC1 as a chemokine receptor for CXCL12/SDF-1 in prostate cancer. J Biol Chem 283(7): 4283-4294.

Williams TM, Lisanti MP (2004) The Caveolin genes: from cell biology to medicine. Ann Med 36(8): 584-595.

Yan X, Cai S, Xiong X, Sun W, Dai X, Chen S, Ye Q, Song Z, Jiang Q, Xu Z (2012) Chemokine receptor CXCR7 mediates human endothelial progenitor cells survival, angiogenesis, but not proliferation. J Cell Biochem 113(4): 1437-1446.

Zabel BA, Wang Y, Lewen S, Berahovich RD, Penfold ME, Zhang P, Powers J, Summers BC, Miao Z, Zhao B, Jalili A, Janowska-Wieczorek A, Jaen JC, Schall TJ (2009) Elucidation of CXCR7-mediated signaling events and inhibition of CXCR4-mediated tumor cell transendothelial migration by CXCR7 ligands. J Immunol 183(5): 3204-3211.

Zheng K, Li HY, Su XL, Wang XY, Tian T, Li F, Ren GS (2010) Chemokine receptor CXCR7 regulates the invasion, angiogenesis and tumour growth of human hepatocellular carcinoma cells. J Exp Clin Cancer Res 29: 31.

This work is published under the standard license to publish agreement. After 12 months the work will become freely available and the license terms will switch to a Creative Commons AttributionNonCommercial-Share Alike 3.0 Unported License. 